\title{
An extended TRANSCAR model including ionospheric convection: simulation of EISCAT observations using inputs from AMIE
}

\author{
P.-L. Blelly ${ }^{1}{ }^{*}$, C. Lathuillère ${ }^{2}$, B. Emery ${ }^{3}$, J. Lilensten ${ }^{2}$, J. Fontanari ${ }^{1}$, and D. Alcaydé ${ }^{1}$ \\ ${ }^{1}$ Centre d'Etude Spatiale des Rayonnements, Toulouse, France \\ ${ }^{2}$ Laboratoire de Planétologie de Grenoble, Grenoble, France \\ ${ }^{3}$ High Altitude Observatory, Boulder (Co), USA \\ *Present address: Laboratoire de Physique et de Chimie de l'Environnement, Orleans, France
}

Received: 24 June 2004 - Revised: 13 October 2004 - Accepted: 8 December 2004 - Published: 28 February 2005

\begin{abstract}
The TRANSCAR ionospheric model was extended to account for the convection of the magnetic field lines in the auroral and polar ionosphere. A mixed EulerianLagrangian 13-moment approach was used to describe the dynamics of an ionospheric plasma tube. In the present study, one focuses on large scale transports in the polar ionosphere. The model was used to simulate a $35-\mathrm{h}$ period of EISCAT-UHF observations on 16-17 February 1993. The first day was magnetically quiet, and characterized by elevated electron concentrations: the diurnal $\mathrm{F}_{2}$ layer reached as much as $10^{12} \mathrm{~m}^{-3}$, which is unusual for a winter and moderate solar activity $\left(\mathrm{F}_{10.7}=130\right)$ period. An intense geomagnetic event occurred on the second day, seen in the data as a strong intensification of the ionosphere convection velocities in the early afternoon (with the northward electric field reaching $150 \mathrm{mV} \mathrm{m}^{-1}$ ) and corresponding frictional heating of the ions up to $2500 \mathrm{~K}$. The simulation used time-dependent AMIE outputs to infer flux-tube transports in the polar region, and to provide magnetospheric particle and energy inputs to the ionosphere. The overall very good agreement, obtained between the model and the observations, demonstrates the high ability of the extended TRANSCAR model for quantitative modelling of the high-latitude ionosphere; however, some differences are found which are attributed to the precipitation of electrons with very low energy. All these results are finally discussed in the frame of modelling the auroral ionosphere with space weather applications in mind.
\end{abstract}

Key words. Ionosphere (Auroral ionosphere; Plasma convection; Modelling and forecasting)

\section{Introduction}

While the climatology of the ionosphere is relatively well understood and modelled, specification and forecast models of what is now called the ionosphere weather is the challenge

Correspondence to: D. Alcaydé

(Denis.Alcayde@cesr.fr) of today. This weather is defined as the hour-to-hour, dayto-day, week-to-week variability of the electron and ion concentrations and temperatures within the framework of the climatology defined by diurnal, seasonal, solar cycle and magnetic storm variations. The various processes of the solar, interplanetary, magnetosphere, ionosphere-thermosphere system that act to define this weather are today relatively well known, e.g. Schunk (2001); Lathuillère et al. (2002). Recent physical modelling is based on global circulation models of the ionosphere-thermosphere system coupled with time varying auroral energy inputs based on empirical models or observations, e.g. Codrescu et al. (1997); Fuller-Rowell et al. (1996); Emery et al. (1999); Roble (2001). But these timevarying studies were mostly successful in dealing with midlatitude observations of the ionosphere/atmosphere, which are mainly controlled by the diurnal/seasonal solar EUV source, with magnetospheric inputs as global perturbations. At mid-latitudes, these codes were mostly successful to correctly quantify the storm-time F-region ionospheric response. However, to our knowledge, there was no case study modelling which was able to describe accurately the threedimensional and time-dependent distribution of the ionospheric plasma during quiet and disturbed conditions in the auroral and polar ionospheres. As Codrescu et al. (1997) pointed out, their mid-latitude plasma density comparisons are good, while matching the structure in the polar cap and auroral zone is poor since they used statistical patterns based on the estimated hemispheric power as high-latitude precipitation and electric field inputs. Indeed, as shown by David et al. (2002), at high-latitudes the coupling mechanisms with the magnetosphere and the interplanetary medium are of the same order, or even preponderant, as compared to the solar EUV control: the physical modelling must take into account the time-dependent transport of the ionospheric plasma along a flux tube, but also the transport of the flux-tube itself by the ionospheric convection. Most recent observations, using, in particular, radar coordination campaigns (Valladares et al., 1999; Carlson et al., 2002), aim at understanding the formation of localized ionospheric structures. Patchy struc- 
tures as observed near the cusp and in the high-latitude ionosphere, were modelled as responses to combined effects of ion and the electron precipitation, and convection electric field (Balmforth et al., 1999; Millward et al., 1999; VontratReberac et al., 2001). Pitout and Blelly (2003) showed that the overall result of cusp precipitation depends on the origin of the flux tube that opens in the cusp region, and therefore is dependent on the season, as well as on the interplanetary magnetic field configuration and on the magnetic local time. But the subsequent transport of patches of ionization across the polar cap, far from their production region (Crowley et al., 2000), remains to be fully described and understood. The work presented in this paper adds to this modelling effort of the high-latitude ionosphere, and focuses on large scale transport. In the first part, we describe the new TRANSCAR model that accounts for both the convection of magnetic field lines and the temperature anisotropies that may arise from intense ion drag and divergence of the magnetic flux tube. This model couples a fluid and a kinetic code and uses time-dependent particle and energy inputs given by the AMIE procedure. It is used to simulate a 35-h EISCAT experiment performed on 16-17 February 1993 at Troms $\varnothing$ $\left(69^{\circ} \mathrm{N}, 19^{\circ} \mathrm{E}, 66^{\circ}\right.$ magnetic latitude). Observations are presented in Sect. 3 and results of the simulation in Sect. 4. In the conclusion, we outline the potential applications of such physical modelling.

\section{The new TRANSCAR model}

\subsection{3-moment fluid description}

Time-dependent transport models, with various levels of approximations, were initially developed and intercompared in order to test the ability of each approximation to represent ionospheric behaviors (Blelly and Schunk, 1993). Starting from the standard approach with the continuity, momentum and energy equations, complemented with the computation of the heat flow from Fourier's law, an 8-moment model was built, fully tested, and calibrated using EISCAT observations. This model uses the hypothesis of an isotropic Maxwellian distribution function and adds the isotropic heat flux equation to the standard set of equations to be solved. Each timedependent equation is then solved for individual ions (see below), as well as for the thermal electron population. A full model description was detailed by Blelly et al. (1996b) and different numerical algorithms were intercompared by Robineau et al. (1996). After an initial ionospheric application and description (Diloy et al., 1996), the model was carefully calibrated using EISCAT observations (Blelly et al., 1996a), and subsequently and extensively used for ion composition (Lathuillère et al., 1997), conductivities (Lilensten et al., 1996) or total electron content (Lilensten and Blelly, 2002) studies. The main underlying hypothesis in this version of the model was the pressure isotropy, with effects of thermal diffusion intrinsically included.

Anisotropy effects can be taken into account by assuming bi-maxwellian or even generalized distribution functions.
Such models were also developed (Blelly and Schunk, 1993; Leblanc et al., 2000), but their description falls beyond the purpose of this paper. The new TRANSCAR model still assumes maxwellian distribution functions, and is mostly identical to the 8-moment model as far as the photochemistry is concerned. But this model allows departures from isotropic behavior for the pressure tensor, through the stress tensor. Time-dependent "parallel" and "perpendicular" equations are solved for the energy and heat flux terms, leading to the so-called 13-moment approximation. Blelly and Schunk (1993) showed that this approximation is well suited for the collision-dominated ionosphere, where anisotropic temperature features can develop, due to the altitude-divergence of the magnetic flux tube, and be reproduced with a good degree of approximation at medium to high altitudes. This model is also well adapted to produce temperature anisotropies induced by intense friction with the neutrals in the $\mathrm{F}_{1}$-region, during strong ionospheric electric field events. But this particular aspect of temperature anisotropies will not be discussed further in this paper which is focused instead on largescale transports and phenomena, while anisotropies concerning small-scale and sporadic features deserve independent study.

The fluid part of TRANSCAR describes the vertical (or more precisely, the IGRF field-aligned) time-dependent transport of the thermal ionospheric plasma between 90 and $3000 \mathrm{~km}$ altitude. Major ions found in the ionosphere are taken into account and individually solved, namely $\mathrm{O}^{+}, \mathrm{H}^{+}$, $\mathrm{N}^{+}, \mathrm{NO}^{+}, \mathrm{O}_{2}^{+}$and $\mathrm{N}_{2}^{+}$, as well as the thermal electron population. A full description was given by Blelly et al. (1996b) and by Diloy et al. (1996).

\subsection{Kinetic description}

The ionospheric electrons may be separated between the thermal population which is treated as a fluid population in the previous section, and the supra-thermal population. The latter is due to two main sources:

1. Photo-production: the EUV flux energy is higher than typically $10 \mathrm{eV}$, i.e. energetic enough to ionize the different neutral populations of the ionosphere. The extracted electrons - called primary photoelectrons have a kinetic energy equal to the difference between the incident beam and the ionization threshold. The primary electrons can have energy up to about $330 \mathrm{eV}$. Such an energy is high enough to create secondary electrons through collisions; indeed the energy required to create an ion-electron pair is about $35 \mathrm{eV}$. The primary photoelectron production, due to the EUV interaction, can be accurately described with a Beer-Lambert law.

2. Electron precipitation: they occur mostly at highlatitude. The energy of the precipitated electrons is highly variable and ranges from a few tens of $\mathrm{eV}$ to $\mathrm{MeV}$. They are therefore an important source of atmospheric ionization. 
3. Ion precipitation (mainly protons): once the primary electron production is taken into account in the modelling, the treatment of the secondary electrons transport is very similar to the production by electrons (see e.g. Galand et al. (1997); Lilensten and Galand (1998); Galand (2001) and associated special issue). However, ion precipitation will not be considered in the present study.

In the terrestrial ionosphere, precipitating electrons or primary photoelectrons move along the magnetic field lines, creating not only ionization but also heating, excitation and dissociation. During an ionization process, the incident electron is scattered mostly forward, whereas the extracted electron, called the "secondary electron", may be scattered into any direction (Opal et al., 1971). The vertical kinetic transport equation expresses the fact that the variation of the steady-state electron flux with the scattering depth at a given altitude, energy and pitch angle, is the difference between what leaves that energy, altitude or angle slab and what enters it (Strickland et al., 1976). It describes the angular and energy redistributions of the electron flux from the top of the ionosphere to the low E region. This equation can be approximated in a relatively simple way. First, we assume that electrons are predominantly transported along magnetic field lines. Secondly, the motion of the electrons is represented by the motion of their centers of gyration along the magnetic field. The effect of ionospheric horizontal electric fields on the energetic electrons is small and is neglected. The acceleration of the electrons is assumed to have taken place above the modelled altitude range, and local field-aligned potential drops and the mirror force from the converging geomagnetic field are neglected. Finally, we can assume the stationary state for the kinetic transport. The main reason is that the absorption of the supra-thermal particles by the atmosphere is much faster than the changes in the source of those particles. The typical collision frequencies are of the order of one per second, while the precipitation occurs over several seconds to several hours, and the photoelectron production varies in a significant manner over a few minutes, when the Earth rotates. Said in other words, a secondary electron of a few $\mathrm{eV}$ energy has a velocity greater than $1000 \mathrm{~km} / \mathrm{s}^{-1}$, i.e. fast enough to go through the ionospheric F-region in less than a fraction of a second. Therefore, the stationary assumption holds on, and means that any time a supra-thermal particle is absorbed, another one with the same characteristics (in terms of energy and pitch angle) is created. Of course, this also means that the kinetic equation must be solved again any time the external conditions change.

Variations in energy or angle due to collisions are described through differential cross sections, deduced from the total cross sections as described in Lummerzheim and Lilensten (1994), and updated in Culot et al. (2004). An additional energy loss arises from the heating of the ambient thermal electron gas due to hot electrons through thermal electron interactions. This loss comes from the combined effects of two body Coulomb collisions and the collective effect of

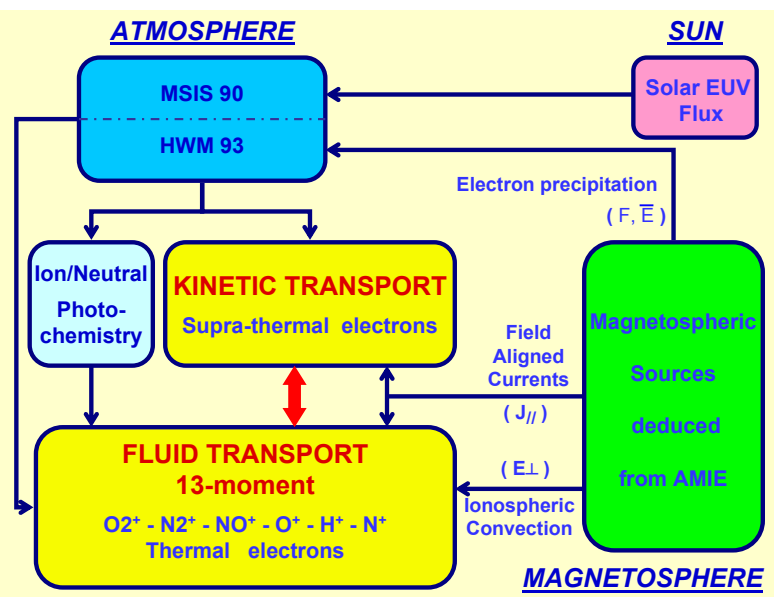

Fig. 1. Synopsis of the TRANSCAR model showing the coupling between the fluid model for the thermal plasma and the kinetic model for the supra-thermal electrons. Inputs from MSIS-90 and HWM-93 neutral atmosphere models and AMIE computations are also shown.

Cerenkov emission of plasma waves. Mantas (1975) treated this loss process as an extra "friction" term, assuming a continuous energy loss of the hot electrons to the ambient electrons, without any deflection during the process. In the literature, this approximation is referred to as "the continuous slowing down approximation" (Swartz and Nisbet, 1972).

The computer program solving the kinetic transport equation, along with complete references concerning the cross sections used in the model, are described in detail by Lummerzheim and Lilensten (1994) and by Lilensten and Blelly (2002), and will not be repeated here.

\subsection{TRANSCAR: kinetic and fluid transports coupled}

The two solvers (yellow boxes in Fig. 1) exchange information through the collision operator. The kinetic module transfers to the fluid module the ion production rate, as well as the heating rate due to the coulomb interaction between the supra-thermal electrons and the thermal population. The fluid module provides the thermal characteristics of the ionospheric thermal electrons to the kinetic module. In Fig. 1, this fluid/kinetic duality is made explicit in the heart of the TRANSCAR model, imbedded in several surrounding boxes which correspond to the external driving sources and dissipative sinks for the ionosphere. Firstly, the SUN (red) box is used to describe the solar EUV spectrum, scaled with a $\mathrm{F}_{10.7}$ index dependence. The ATMOSPHERE (blue) box provides the neutral atmosphere constituents from the MSIS- 90 model (Hedin et al., 1991), used both in the kinetic (energy degradation) and in the fluid (ion-neutral collisions) solvers, and the neutral winds with the HWM-93 model (Hedin et al., 1994), which provides the dynamical coupling of the ionosphere with the neutrals in the fluid module. Finally, the green box gives the magnetosphere-ionosphere interaction, due to the convection which impacts directly on the thermal 


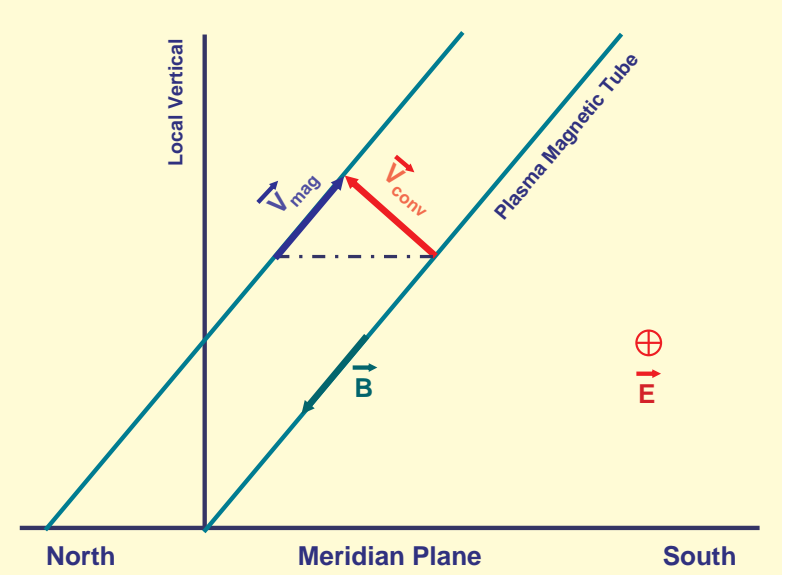

Fig. 2. Sketch explaining the presence of a velocity component $\boldsymbol{V}_{\text {mag }}$ along the magnetic field-line resulting from the ion convection drift $\boldsymbol{V}_{\text {conv }}$.

ionosphere (fluid component) through horizontal transports and friction with the neutral atmosphere, and the magnetosphere energy inputs due to energetic particle precipitation, and to field-aligned currents, which drive both the kinetic and fluid modules of the model. This complex box deserves being described in more detail in the following two sections.

\subsection{Plasma tube convection}

The effects of horizontal transport, as for example, the frictional heating with the neutral atmosphere, are embedded in the new TRANSCAR model (Fig. 1). Despite the fact that horizontal transport is not solved, the magnetic flux tube frozen assumption nevertheless allows for this transport and follows the time evolution of any flux tube transported by the convection electric field. This is valid above $150 \mathrm{~km}$ where the plasma is fully magnetized. Below this altitude, the ions are partially demagnetized, due to strong collisions on neutrals and such an assumption becomes questionable. However, in this narrow region, processes like chemical reactions overcome horizontal transport effects and we may consider that the plasma dynamics is dominated by local processes. Therefore, the lack of description for horizontal transport in this region is not significant.

The main purpose in the present study is to follow the time history of a flux tube, while it is transported in the polar cap by the ionospheric convection. But in doing so we face a technical problem. As a matter of fact, the core module of this ionospheric model is based on an Eulerian description of the transport equations. This means that we follow the dynamics of the ionospheric species in a frame which is fixed with respect to the ground. But the horizontal motion induced by the convection is intrinsically Lagrangian, in the sense that the frame moves with the plasma tube. When the plasma tube is not vertical (Fig. 2), since the convection drift $\boldsymbol{V}_{\text {conv }}=\frac{\boldsymbol{E} \times \boldsymbol{B}}{B^{2}}$ is perpendicular to the magnetic field, we couple the two representations through a drift of

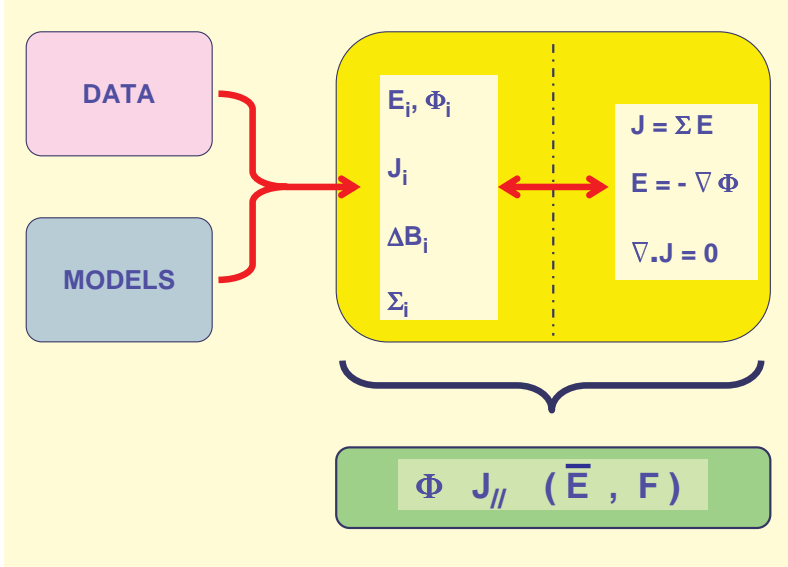

Fig. 3. Synopsis of the AMIE procedure. The outputs for the simulation are the convection potential $\phi$, the field-aligned current $J / /$ and the electron precipitation mean energy $\bar{E}$ and energy flux $F$.

the frame along the magnetic field, which is the "apparent" field-aligned component of the plasma drift $\boldsymbol{V}_{\mathbf{m a g}}$ in the $\mathrm{Eu}$ lerian transport equations. The Eulerian transport equations can then be considered Lagrangian with the addition of this $V_{\text {mag }}$ drift.

The code is built such that the convection drift, which results from external forcing as far as a flux tube is concerned, can result from statistical models of convection, or from observations such as SuperDARN. Knowing the time history of the convection pattern, it is possible to trace back (in space and time) the path of the flux-tube prior to its observation at a given location. The flux tube is then modelled following its horizontal transport. This procedure was applied in the present study. Each 10-min time step flux tube was modelled during the 4-h period preceding the time of their "observation", supposedly in the Troms $\varnothing$ area. This 4-h convection time is larger than the characteristic time of the ionosphere F-region of about $20 \mathrm{~min}$. The neutral atmosphere, which is completely specified in this study by the MSIS-90 and HWM-93 models which can use long time histories of the Ap index, needs longer times to adjust, especially after intense magnetic storms. Numerically speaking, the 4-h period also allows the tube to reach its "numerical dynamical equilibrium". As mentioned above, however, additional magnetospheric sources for the flux tubes are of importance, such as field-aligned currents and energetic electron precipitation, and must be taken into account for real case studies. This has been possible by using AMIE as the magnetosphere source driver for the simulations.

\subsection{Coupling with AMIE}

The Assimilative Mapping of Ionospheric Electrodynamics (AMIE) procedure has been used to derive the timedependent large-scale distribution of the ionospheric convection and particle precipitation. As described in Fig. 3, the AMIE procedure (Richmond and Kamide, 1988; Richmond, 
1992) incorporates observed data, as well as a priori information from empirical models (red and blue boxes) to derive the convection potential $\Phi$, the field-aligned currents $J_{/ /}$ and the electron precipitation energy flux $F$ and mean energy $\bar{E}$ (green box of Fig. 3) that will be used as inputs for the TRANSCAR model. The AMIE grid scale used in this study was $1.7 \mathrm{deg}$ in magnetic latitude and $40 \mathrm{~min}$ in MLT. The data include satellite measurements of ion drifts and particle precipitation, radar observations and ground magnetometer measurements. These data are used in a single weighted least-squares fit of coefficients to determine the spatial distributions of potential $\Phi_{i}$, electric field $E_{i}$, current $J_{i}$, magnetic perturbations $\Delta B_{i}$ and conductivities $\Sigma_{i}$ (left part of the yellow box of Fig. 3). These distributions are linked by the equations shown in the right part of the yellow box of Fig. 3 . Models of electric potential (Foster et al., 1986) and auroral parameters (Fuller-Rowell and Evans, 1987) are used to improve the estimates in the region where the data coverage is sparse.

AMIE outputs over the polar cap and auroral zone are used in TRANSCAR in the following way: the polar cap electric potential $\Phi$ is used to compute the convection velocities, which, in turn, are used to model the dynamics and chemistry of each flux tube during the 4-h time period preceding its "observation". The AMIE convection velocities have been increased by an ad-hoc factor of 2.5 to agree with the largest ion drift observations at Troms $\varnothing$, as explained in Sect. 3.3. Hence, the physical processes occurring during the time history of each flux tube, prior to the "tube observation", are taken into account well, and their signatures are thus present in the simulated tube structure at the time when the tube is supposed to be observed by the radar. The AMIE fieldaligned currents $J_{/ /}$are assimilated as upper boundary heat fluxes for the fluid model (Blelly and Schunk, 1993; Blelly and Alcaydé, 1994), while AMIE energetic electron precipitation flux $F$ and mean energy $\bar{E}$ are inputs for the kinetic model which computes the resulting ion production and energy deposition.

\section{$3 \quad 16-17$ February 1993 observations}

The 16-17 February 1993 is a period which has been extensively studied. On 16 February around 21:00 UT, intense ion outflows have been observed by the Akebono satellite and the EISCAT VHF radar in the nighttime auroral zone (Yoshida et al., 2000). On 17 February, at the Canadian Polar Observatory at Eureka ( $89^{\circ}$ magnetic latitude), auroral Sun-aligned arcs were observed by Oznovich and McEwen (1994), most of them in the early hours until 8:30 UT and again beyond 12:00 UT. In the interval in between, from 9:45 until 11:15 UT, McEwen et al. (1995) observed, by optical means and a digital ionosonde, drifting $\mathrm{F}$ layer ionization patches. Although no interplanetary magnetic field observations are available for these two days, the papers cited above show that the coupling between the magnetosphere and the ionosphere plays a major role in the small-scale structures observed.

\subsection{Geophysical context}

Our period of interest occurs during the declining phase of Solar cycle 22 with a $F_{10.7}$ solar index of about 130.16 February is one of the most magnetically quiet days of the month, with a daily Ap index equal to 6, while 17 February is classified as a very active day, with a daily Ap index equal to 36. Unfortunately, no IMF data are available for this 2-day period. Figure 4 (top panel) shows the temporal evolution of the $\mathrm{AE}(56)$ auroral index and the Ap three-hour index for the 35-h EISCAT observations. The AE(56) auroral index is calculated from 5-min average magnetometer data from 56 of the 112 magnetometers used in the AMIE procedure that lie between 55 and 76 magnetic latitude (52 in the north, and only 4 in the south). The standard AE index $\mathrm{AE}(12)$ is based on only 12 stations in the Northern Hemisphere and can miss the intense electrojet regions for very active or very quiet conditions. The $56 \mathrm{AE}$ stations used in the AMIE procedure $\mathrm{AE}(56)$ thus represent the magnetic activity more accurately. During the first $4 \mathrm{~h}$, there is a small increase in the $\mathrm{AE}(56)$ index which indicates that some auroral currents are flowing in the ionosphere. $\operatorname{AE}(56)$ increases more significantly on 17 February, with a large maximum around 14:00 UT. This large increase is also shown in the planetary index which maximizes at 111 between 12:00 and 15:00 UT. (Note that the 3-h Ap indices (no units) have been multiplied by 5 and put on the same scale as $\mathrm{AE}(56)$ in $\mathrm{nT}$ ). The two other panels of Fig. 4 show, respectively, the magnetic field recorded at the Troms $\varnothing$ Geophysical Observatory and the ionospheric electric field (modulus) deduced from the EISCAT UHF tristatic observations and the corresponding one resulting from AMIE computations, scaled to the observation by a factor of 2.5 (this scaling will be discussed later in Sect. 3.3). Both panels show a small activity at noon and in the afternoon sector on 16 February, while a large activity develops, with the electric field at Troms $\varnothing$ reaching $130 \mathrm{mV} \mathrm{m}^{-1}$ around 14:00 UT the next day.

\subsection{EISCAT-UHF data}

The EISCAT-UHF system was running almost continuously for the $35 \mathrm{~h}$ starting on 16 February at 10:00 UT, with a 1-h interruption between 01:00 and 02:00 UT on 17 February, and a few shorter interruptions, most of them between 7:00 and 12:00 UT. The EISCAT-VHF radar was also running in a high altitude mode with the antenna pointing vertically. VHF data which allow the investigation of the very high altitude ionosphere have been used to study the ion outflows observed by the Akebono satellite (Yoshida et al., 2000). They are, however, not used in our own study, whose main interest is the $F_{2}$ region behavior. The Troms $\varnothing$ UHF antenna was aligned to the geomagnetic field line and Kiruna and Sodankylä looked at a common volume at $278 \mathrm{~km}$ altitude, allowing for the inference of the electric field in Fig. 4. 


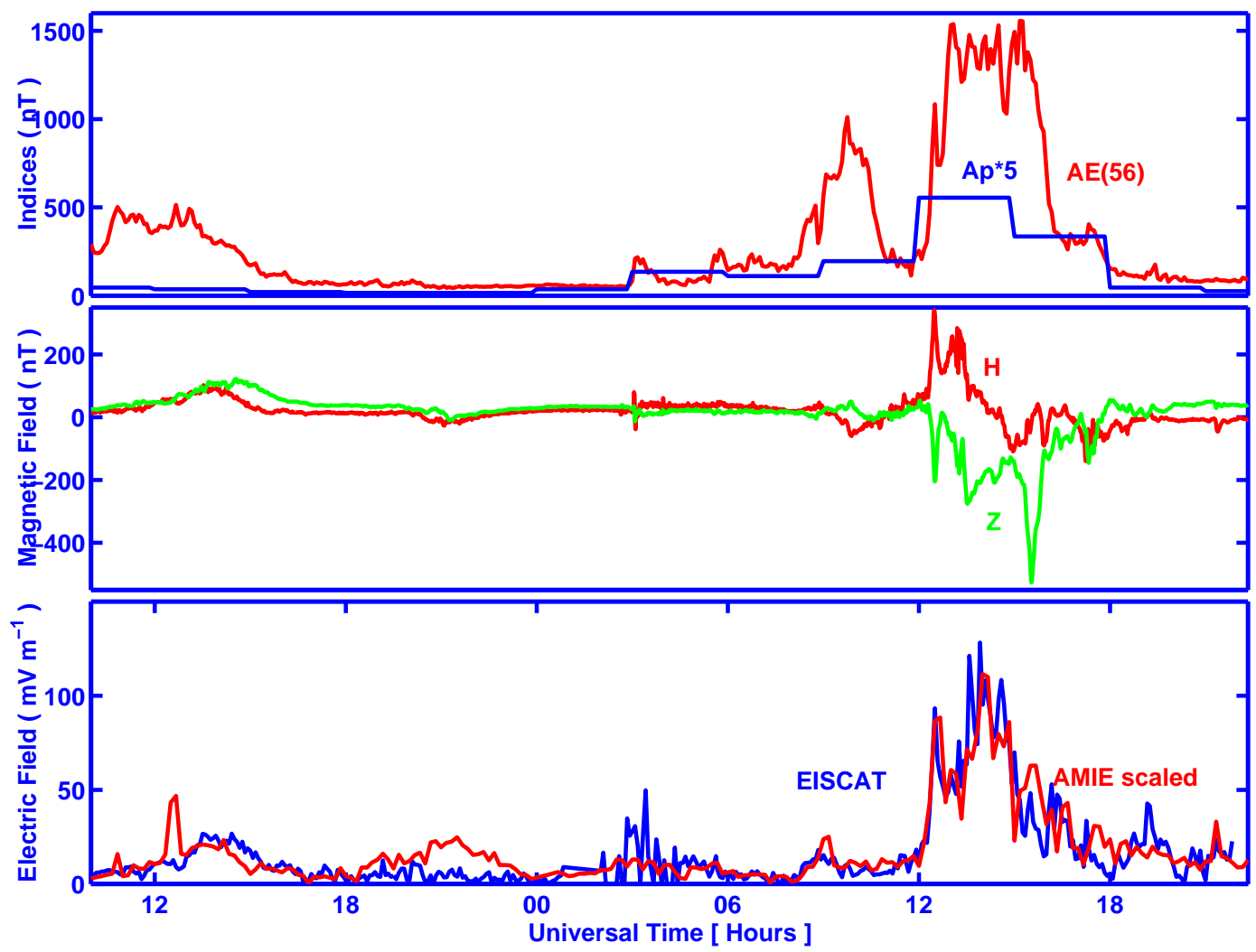

Fig. 4. From 16 February 1993 at 10:00 UT, to 17 February 1993 at 21:00 UT: Top panel: temporal evolution of geophysical indices Ap and $\mathrm{AE}(56)$. Middle panel: horizontal $(\mathrm{H})$ and vertical $(\mathrm{Z})$ component of the Troms $\varnothing$ magnetometer. Bottom panel: modulus of the electric field inferred from EISCAT-UHF tristatic measurements, and the corresponding scaled electric field resulting from AMIE computations (see text).

We used a post integration time of $1 \mathrm{~min}$. The time/altitude color plot of the electron density, the electron temperature, the ion temperature and the ion velocity are displayed in Fig. 5 (from top to bottom). During daytime one observes on the top panel a very well-defined $F$ layer. The diurnal $F_{2}$ peak electron density reaches surprisingly to $10^{12} \mathrm{~m}^{-3}$ during this period of low solar activity and winter conditions. More typical values are almost a factor of 2 lower, as can be seen in the F2 region parameters for 3 March 1993 and 9 February 1999 (see the Grenoble Eiscat database at http://www-eiscat.ujf-grenoble.fr). In the evening of 16 February, F-region patches can be seen. The first of them is associated with an increase in the electron temperature, as can been seen on the second panel. This suggests that they may be due to soft electron precipitation. Much harder precipitation occurs on 17 February, starting just after 12:00 UT and results in enhanced densities at $\mathrm{E}$ region altitudes, and enhanced electron temperatures. The main feature of the ion temperature (third panel of Fig. 5) is the large ion frictional heating event between 12 and 14:00 UT on 17 February, associated with the large electric field observed at this time. The ion temperature increases above $2500 \mathrm{~K}$. It is worthwhile to note that the data presented here are obtained with a normal analysis of incoherent scatter data, that does not take into account non-maxwellian ion velocity distribution functions
(St Maurice and Schunk, 1977; Hubert, 1984), or changes in the ion composition (Kelly and Wickwar, 1981; Lathuillère, 1987; Lathuillère et al., 1997), that are likely to occur during very high electric field periods. Therefore, the ion temperature minimum around $250 \mathrm{~km}$ altitude is just an analysis artifact, and the overall ion and electron temperature increase must be considered an underestimate (Lathuillère and D. Hubert, 1989). The bottom panel of Fig. 5 shows the ion velocity parallel to the magnetic field, positive upwards. One can note at $F$ region altitudes a succession of periods corresponding to upward and downward velocities. In particular, the upward velocities observed between about 300 and $600 \mathrm{~km}$ just before 21:00 UT on 16 February are associated with ion outflows oberved by the Akebono satellite (Yoshida et al., 2000). On 17 February much stronger features of upward and downward flows occur successively, mainly after 12:00 UT above about $400 \mathrm{~km}$.

\subsection{AMIE inputs}

For 16-17 February, AMIE data sets include 112 ground magnetometers including the CANOPUS network, the Greenland network, the IMAGE network, the SAMNET network, the 210 magnetometer chain, and magnetometer data from the World Data Center A in Boulder Colorado. Ion 


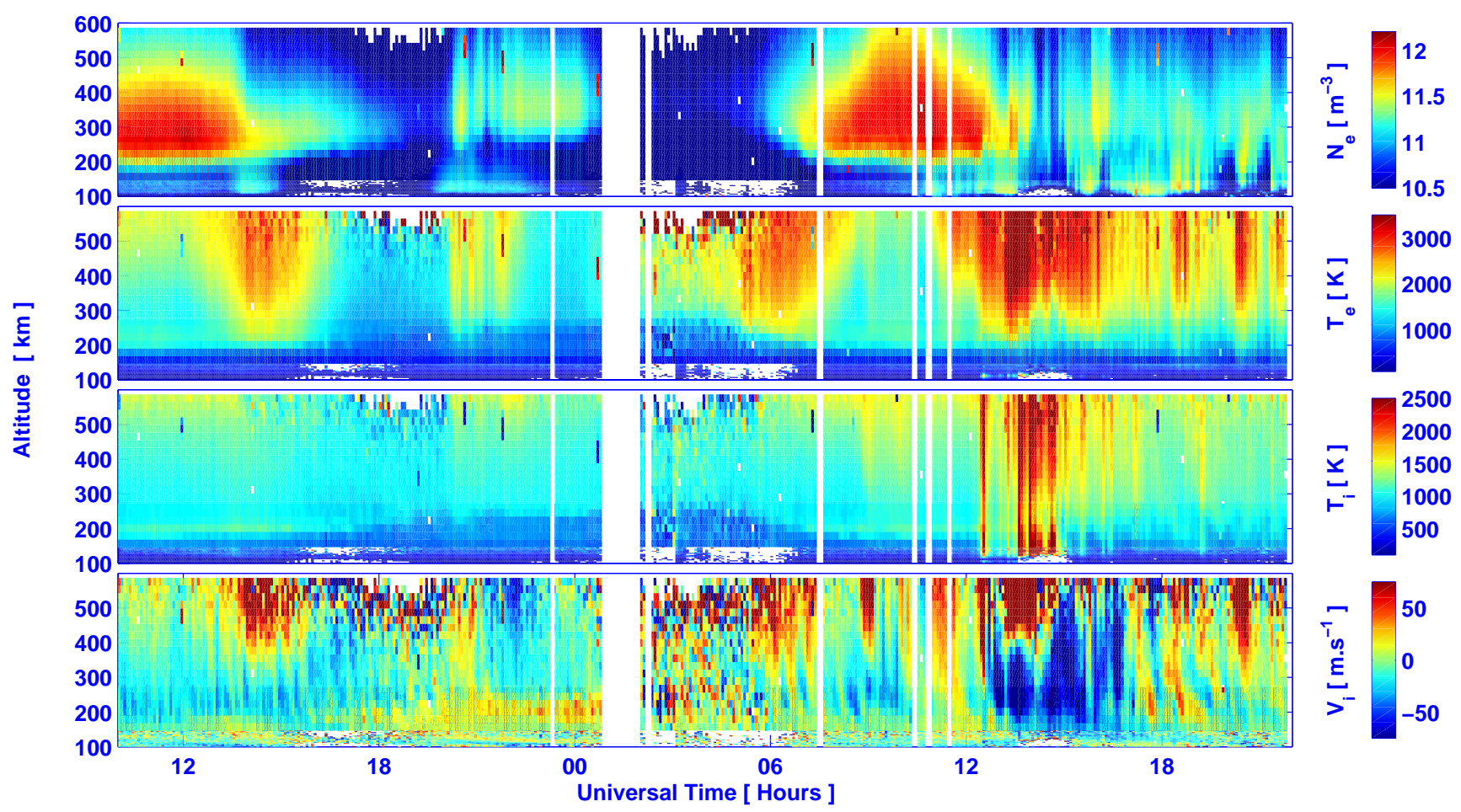

Fig. 5. From top to bottom: Time/altitude color plot of the electron concentration ( $\log _{10}$ scale), the electron temperature, the ion temperature and the line of sight ion velocity, from UHF CP1 Common Program observations, for the same period as Fig. 4. Local noon corresponds to 10:40 UT.

drift velocities have been obtained from the EISCAT radar, the Goose Bay HF radar and the DMSP F08, F10 and F11 satellites. Finally, the electron precipitation has been derived from the same DMSP satellites, as well as the NOAA-12 satellite, assuming a Maxwellian distribution. AMIE outputs are obtained every $10 \mathrm{~min}$ for the Northern and Southern Hemispheres independently. Only the Northern Hemisphere data have been used in the present study.

Figure 6 shows the temporal evolution of some AMIE outputs. The top panel shows the cross-tail convection potential drop and the total hemispheric power (HP) that drive, respectively, the Joule and particle auroral heating inputs to the ionosphere-thermosphere system. The convection potential reaches $50 \mathrm{kV}$ a few times on 16 February and $140 \mathrm{kV}$ near 14:00 UT on 17 February. The electric fields from the convection potential have been multiplied by a factor of 2.5 , in order to obtain electric fields above Troms $\varnothing$ of the same order of magnitude as those observed by EISCAT (see Fig. 4). Let's remember that the AMIE procedure deduces the convection patterns from different sets of data, resulting in a smoothing of small-scale structures present in the original data. Samplings over 10-min time steps, and over $1.7 \mathrm{deg}$ in latitude, are also likely to contribute to a smoothing out of large time variability. In the TIEGCM simulations of the November 1993 storm period, which used AMIE time-dependent inputs to take into account the variability of the electric field and its small-scale structures (Emery et al.,
1999; Codrescu et al., 1995), the Joule heating term, which is approximately proportional to the square of the ion velocity in the neutral temperature equation, was multiplied by a factor of 1.5 in the Summer Hemisphere, and 2.5-scaling in the Winter Hemisphere. In addition, predictions of the Global Geospace Circulation Model have led to polar cap potential drops that are roughly a factor of 2 larger than those predicted by AMIE (Raeder et al., 1998). Such a factor between magnetohydrodynamic simulations and AMIE results has also been found by Fedder et al. (1998) and discussed in detail. However, cases were also reported in which the cross-tail potential from the MHD model was comparable to AMIE results (Slinker et al., 1999). In the following simulations, the 2.5 scaling factor, obtained to match the local electric field Troms $\emptyset$ measurement to AMIE convection, has been applied to determine the 4-h convection of each flux tube. This factor proved to work in the present case simulations, but must be considered as an ad hoc one, not to be generalized for other studies.

The hemispheric power is a measurement of the total energy input into the ionosphere-thermosphere system from precipitating electrons. Its time variation follows the $\mathrm{AE}(56)$ index presented in Fig. 4, with, in particular, a large maximum from 12:00 UT to almost 18:00 UT on 17 February. The bottom panel of Fig. 6 displays the mean energy and the energy flux of the precipitation above Troms $\varnothing$ as given by AMIE. One can see that the energy flux is significant only 


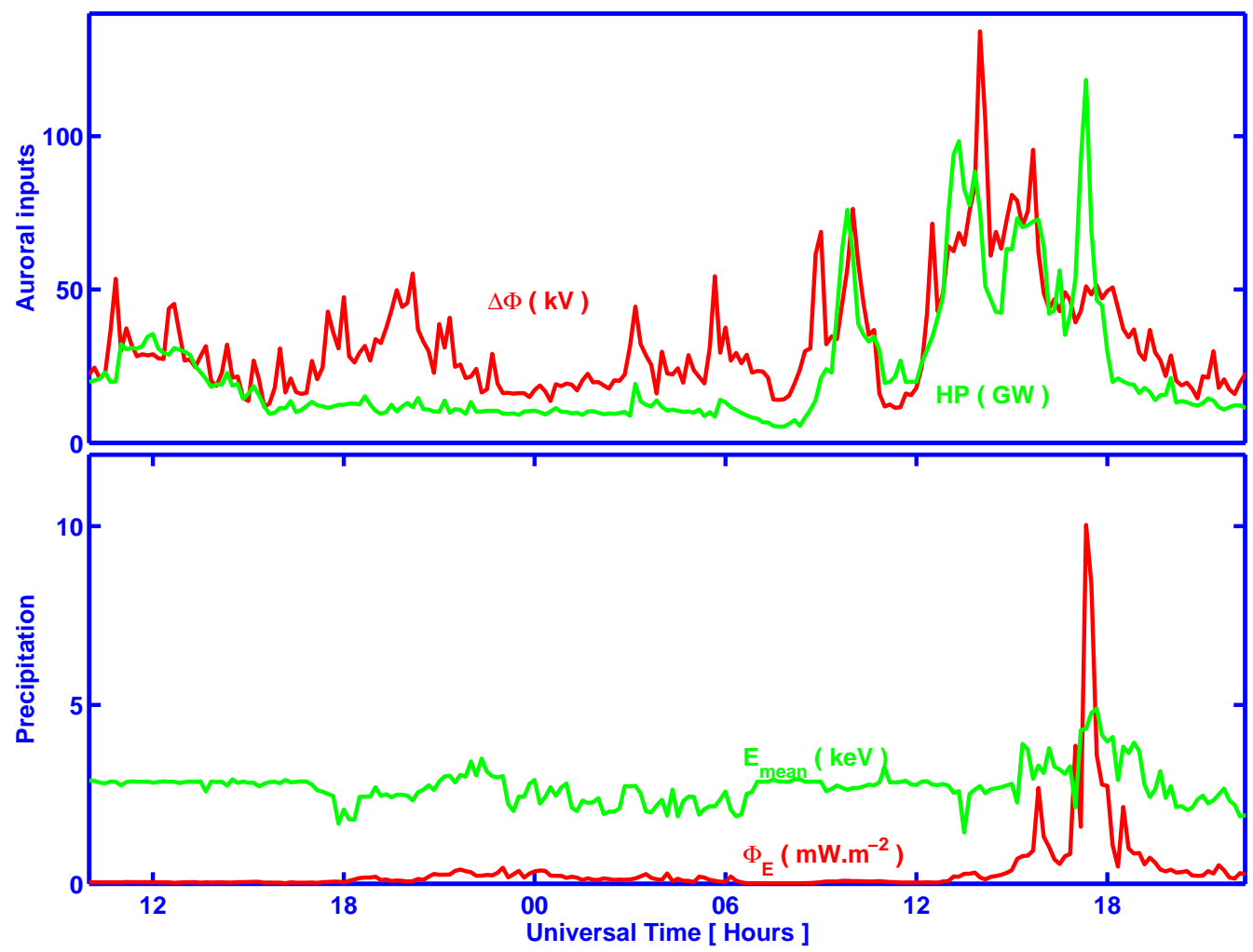

Fig. 6. Top: temporal evolution of the Northern Hemisphere cross polar cap potential $(\Delta \phi$ in $\mathrm{kV})$ and particle hemispheric power (HP in GW). Bottom: electron precipitation mean energy $\left(E_{\text {mean }}\right.$ in $\left.\mathrm{keV}\right)$ and energy flux $\left(\phi_{E}\right.$ in $\left.\mathrm{mW} / \mathrm{m}^{-2}\right)$ above Troms $\varnothing$. Parameters computed by AMIE for the same period as Fig. 4 .

between 15:00 and 19:00 UT on 17 February and that at this time the mean energy increases to about $5 \mathrm{keV}$. This is consistent with the increase of $\mathrm{E}$ region ionospheric densities observed by EISCAT (Fig. 5).

\section{Results of the simulation}

\subsection{Simulation overview}

Figure 7 displays the simulation results, for the same period as for the EISCAT observations in Fig. 5, and with the same altitude and color scales. This figure displays, for every 10min time step, the flux tube arriving above EISCAT after four hours of convection during which they were subject to the varying solar illumination and varying energy inputs provided by AMIE results.

At a first glance, the simulation reproduces quite well many observed structures. In addition to the solar production patches of ionization around noon on 16 and 17 February, the simulation quantitatively reproduces the frictional event seen in the ion temperatures between 12:00 and 15:00 UT the second day, which results from the high convection drift disturbance reaching $150 \mathrm{mV} \mathrm{m}^{-1}$ above Troms $\emptyset$ using the scaled AMIE ion drifts. The disturbance also results in a strong electron temperature increase, originating in the thermoelectric effect which induces a field-aligned current which heats the thermal electrons. This field-aligned current is obtained from the AMIE magnetospheric drivers (see Fig. 1).

The simulation also gives a rather good representation of the sporadic behavior of the structure and dynamics of the ionosphere after the peak of the event. Some electrodynamic behaviors are also well reproduced, such as, for example, the ion outflows above about $300 \mathrm{~km}$, associated with high electron temperatures around 14:00 UT (sunset) for both days, and starting around 06:00 UT (sunrise) on 17 February. These are well known effects of heat flow around sunrise and sunset in the polar ionosphere (Blelly and Alcaydé, 1994).

All is not perfect, however. During quiet periods, and specifically during the night between 21:00 and 24:00 UT, EISCAT observations show patches of ionization in the Fregion that the simulation is unable to reproduce. However, the faint electron concentration increases, seen on the data at E-region heights during the same period, are more or less well reproduced by the simulation. This illustrates the limits of the present simulation, which is based on an integrated analysis by AMIE of the E-region electrodynamics, which only considers energies above $460 \mathrm{eV}$ from DMSP satellites in order to estimate the electron spectrum as a Maxwellian distribution (Rich et al., 1987). The Robinson et al. (1987) formulas for the Pedersen and Hall height integrated conductances, which are primarily sensitive to currents in the E-region, are used to convert the auroral mean electron en- 


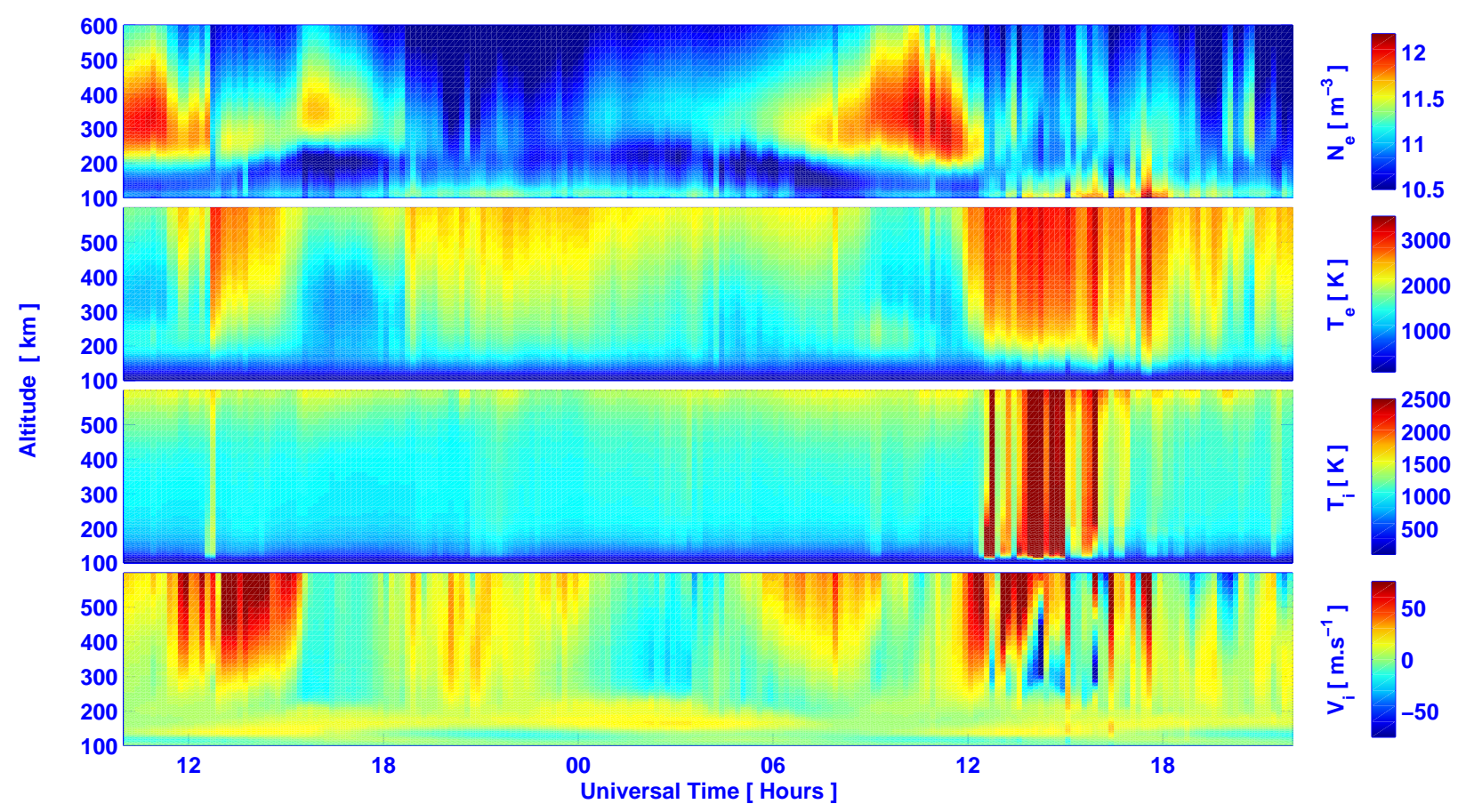

Fig. 7. From top to bottom: Time/altitude color plot of the electron concentration ( $\log _{10}$ scale), the electron temperature, the ion temperature and the line of sight ion velocity, from TRANSCAR simulation, for the same period as Fig. 4.

ergy flux and mean energies to conductances. Thus, AMIE does not consider low energy electron precipitation which produces F-region ionization such as that seen by Akebono during conjunction passes (Yoshida et al., 2000). Hence, the simulation fails to reproduce these features.

\subsection{Effect of the convection on the diurnal $F_{2}$ peak}

These EISCAT observations were made during characteristically quiet time periods, mainly on 16 February, followed by an event of strong electric field disturbance in the post noon sector of 17 February reaching $150 \mathrm{mV} \mathrm{m}^{-1}$ at the maximum of the disturbance. High electron density patches at F-region heights are seen in the data, following the disturbance in the evening sector. The simulation reproduces, at least qualitatively, such occurrences of patches of ionization passing over the radar. The time history of individual flux-tubes with such patches shows that the density intensification results from a transpolar transport of flux tubes from sunlit and lower latitude regions, with northward trajectories from the sunlit afternoon sector ionosphere, followed by a southward transport until the observation time. During the northward transit, the ionospheric plasma was lifted up by the convection (Fig. 2), to higher altitudes, reducing the chemical recombination and hence enhancing its lifetime. The patch occurrences, in these cases, are therefore understood as being fossil traces of the sunlit ionosphere. The structures are transported in the night sector in complex paths due to the disturbance event which resulted in a complex reorganization of the polar cap potential distribution, and hence of the convection patterns. This is shown in Fig. 8a which displays the path of a flux tube arriving in the radar field-of-view at 18:00 UT. During the 4-h time period preceding the observation, the flux tube trajectory is modified every $10 \mathrm{~min}$ (i.e. the AMIE result sampling) to follow the scaled AMIE convection.

Another intriguing feature is the high electron concentrations at the $\mathrm{F}_{2}$-region peak observed during the quiet period, for example, around noon on 16 February the concentration reaches $10^{12} \mathrm{~m}^{-3}$, during wintertime and moderate solar activity $\left(F_{10.7}=130\right)$. One of the simulation purposes was to understand how the ionosphere can be so dense under these conditions. Figure $8 b$ shows the path of the flux tube that arrives above Troms $\emptyset$ at 11:20 UT, during the 4-h time period preceding the observation.

Figure 9 plots the time evolution of this flux tube during its convection. The top panel shows the time variation of the solar zenith angle seen by the plasma during its convection (red curve) as compared to the solar zenith angle at the radar location (green curve). The second panel shows the electric field components seen by the flux tube during its transport, as deduced from the scaled AMIE convection potential, and the bottom panel plots the corresponding electron density time-altitude profile. At the beginning of the period, until 09:00 UT, the flux tube is at a lower latitude than the EISCAT radar with a much lower solar zenith angle. The plasma in the tube is sunlit and undergoes a continuous increase of density due to the solar production. Then, between 9:00 and 10:30 UT, the flux tube is rapidly transported to higher latitudes by the northward convection induced by the 

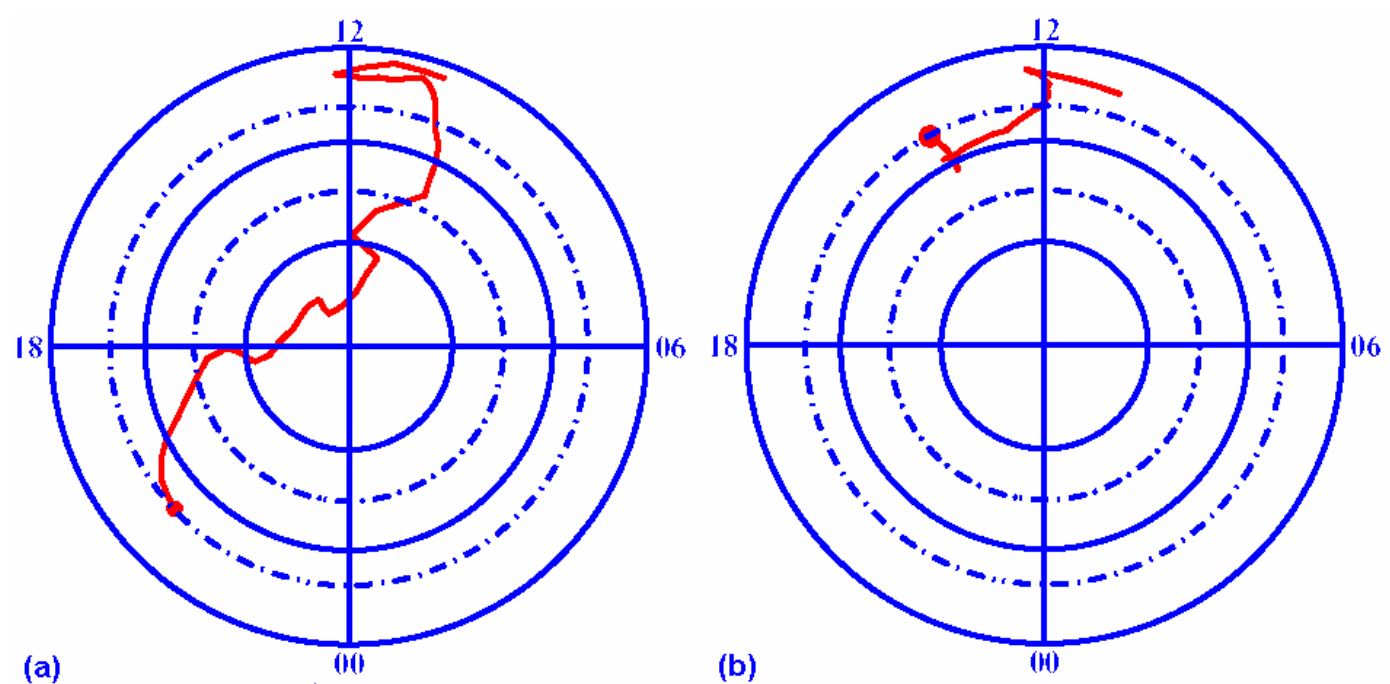

Fig. 8. Path history during the four preceding hours of the magnetic flux tube arriving (red dot) at 18:00 UT above Troms $\varnothing$ on 17 February, left-hand side (a) and at 11:20 UT on 16 February, right-hand side (b). The tube trajectories (red lines) and the location of EISCAT-Troms $\emptyset$ radar (outer dashed circles) are plotted in the MLT frame between $60^{\circ}$ and $90^{\circ}$ magnetic latitude.

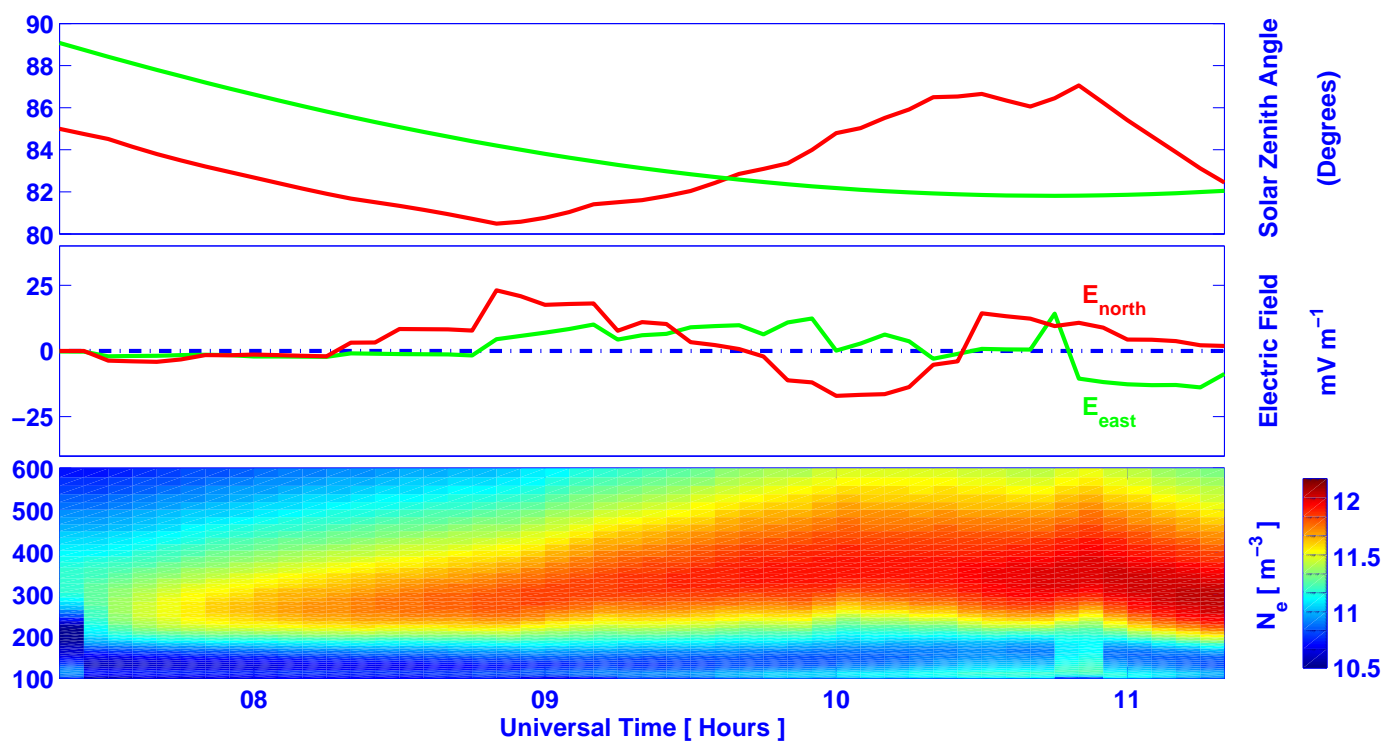

Fig. 9. Historical evolution of the magnetic flux tube arriving at 11:20 UT above Troms $\emptyset$. From top to bottom: solar zenith angle of the flux tube (red line) compared to the solar zenith angle at the EISCAT location (green line), northward and eastward electric field components in the flux tube, and color-coded field-aligned time-altitude profiles of the electron density ( $\log _{10}$ scale).

positive $E_{\text {east }}$ electric field, resulting in an upward drift of the F-region peak, lifting up the plasma at altitudes where its chemical lifetime is larger. Despite the associated decompression of the plasma, the electron concentration continues to increase as the photo-production continues to be effective in this still sunlit region. Finally, just before 11:00 UT, the convection rapidly transports the tube southwards, with a rapid descent of the plasma along the field line. This upwards/downwards mechanism is not symmetric in time - the descent results in a compression of the plasma which induces a further increase of the densities, whereas the chemistry in the lower F-region, which starts to play a role again, is not fast enough to compensate for the compression. This series of transport mechanisms thus explains the surprising high densities observed by the radar around noon, very well reproduced by the simulation.

\section{Conclusions and space weather outlook}

The study has used the new TRANSCAR model coupled with AMIE results to model a 35-h set of EISCAT UHF ob- 


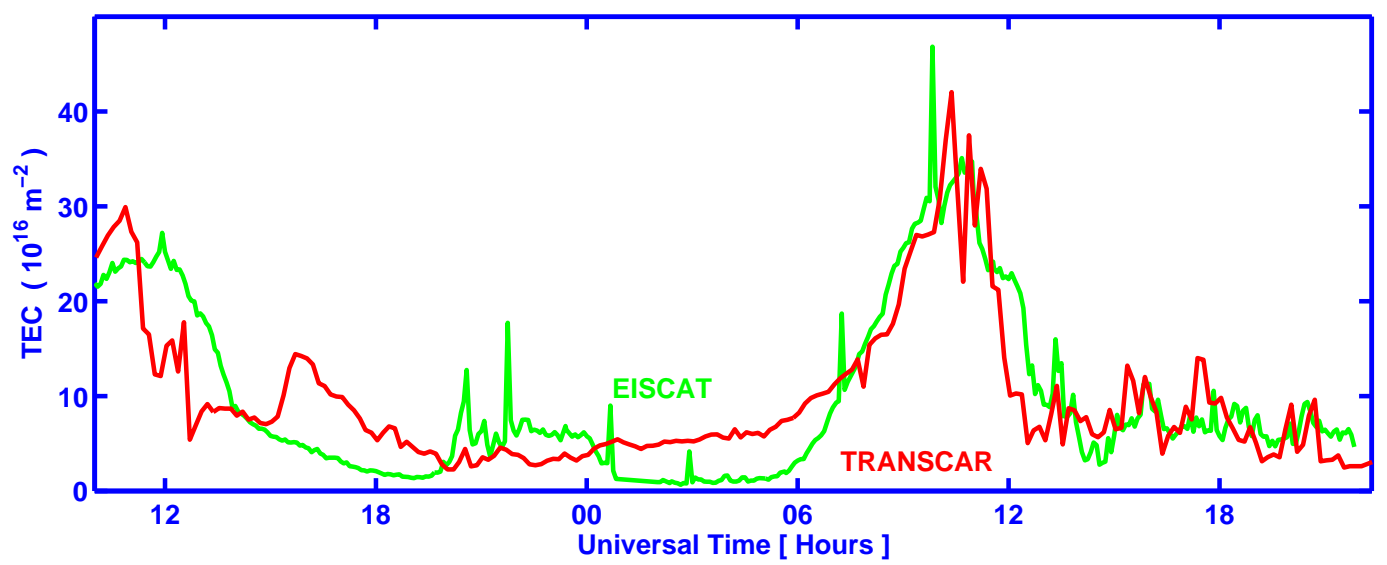

Fig. 10. Temporal evolution of the total electron content observed by EISCAT (green line) and calculated by TRANSCAR (red line), for the same period as Fig. 4 .

servations; AMIE outputs were used to infer the convection ion drifts (scaled by 2.5) from the polar cap potential, electron precipitation and field-aligned current distributions during the period of observations. For each TRANSCAR time step (5 $\mathrm{min}$ ), the observed flux-tube was modelled during its transport by the convection $4 \mathrm{~h}$ prior its arrival at the radar location. Most of the large-scale features seen by the radar during its 35-h observations are well reproduced by the simulation. The main results of the data/model comparison can be summarized as follows:

1. Some features result from local and more or less instantaneous mechanisms, such as the ion heating due to friction during the electric field event the second day; the electron heating around sunrise and sunset can also be considered as a "local" mechanism;

2. But many other features result from pure transport mechanisms, as the very high electron densities observed by the radar around noon the first day, or patches of ionization in the F-region, transported from other places by the convection.

3. The simulation has also shown its limits, due to the inability of AMIE to reproduce the low-energy electron precipitation, and the corresponding F-region production, seen in the radar data and not reproduced.

Figure 10 shows the total electron content (TEC) as deduced from EISCAT observations and the results from TRANSCAR: an overall very good agrement is found. But the lack of information on specific F-region production, due to very soft particle precipitation, may significantly contribute to the TEC. Figure 10 shows that the high altitude production during the night (20:00-24:00 UT the first day) contributes significantly to the TEC and is not well reproduced by the simulation. The simulation also demonstrated the fact that the ionospheric convection plays a crucial role in the auroral/polar ionosphere, not only for the local dynamics, but also for the redistribution, all over the polar regions, of "fossil" structures created elsewhere prior to their observation. In this case study, the 1-D-ionosphere model (fieldaligned), coupled with a description of the convection and spatial distribution of magnetospheric inputs, allows a simplified (or pseudo), 3-D modelling of the ionosphere.

This demonstrates the feasibility of a realistic modelling of the polar ionosphere, and steps towards a workable model of the polar ionosphere for space weather purposes, provided there is a parameterized model of the magnetosphere inputs to the ionosphere with four key parameters - the convection potential, the field-aligned currents and both softand high-energy electron precipitation. One further step towards a self-consistent model is under progress. The aim is to couple TRANSCAR with the Ionosphere-Magnetosphere Model (Peymirat and Fontaine, 1994), which can provide these magnetospheric key parameters.

We shall also keep in mind that TRANSCAR relies on the ability of empirical thermospheric models to correctly describe the polar neutral atmosphere. Progress is needed, particularly for the description of intense storms.

Acknowledgements. EISCAT is an international association supported by the Research Councils of Finland (SA), France (CNRS), the Federal Republic of Germany (MPG), Japan (NIPR), Norway (NFR), Sweden (VR) and the United Kingdom (PPARC). TRANSCAR developments were supported by CNRS through the successive programs "GdR Plasmae" and "Programme National Soleil Terre". We thank L. Morris at the World Data Center A in Boulder for selecting ground magnetometer data, the Canadian Space Agency and T. Hughes at the National Research Council of Canada for providing data from the CANOPUS magnetometer array, $\mathrm{T}$. Moretto of the Danish Meteorological Institute for the Greenland magnetometer network, D. Milling of the University of York for the SAMNET magnetometer array, H. Lühr of the Technical University of Braunschweig for the IMAGE magnetometer data, and K. Shiokawa of Nagoya University and K. Yumoto of Kyushu University for the ground magnetometer data from the 210 chain. We are grateful to F. Rich for providing the DMSP ion drift and electron precipitation data, and to D. Evans for the NOAA-12 electron precipitation observations. Estimates of the particle hemispheric 
power were provided using both NOAA and DMSP satellites from the CEDAR Database at the National Center for Atmospheric Research which is supported by the National Science Foundation.

Topical Editor M. Lester thanks S. Buchert and another referee for their help in evaluating this paper.

\section{References}

Balmforth, H. F., Moffett, R. J., and Rodger, A. S.: Localized structure in the cusp and high-latitude ionosphere: a modelling study, Ann. Geophys., 17, 455-462, 1999,

SRef-ID: 1432-0576/ag/1999-17-455.

Blelly, P.-L. and Alcaydé, D.: Electron heat flow in the auroral ionosphere inferred from EISCAT-VHF observations, J. Geophys. Res., 99, 13 181-13 188, 1994.

Blelly, P. L. and Schunk, R. W.: A comparative study of the timedependent standard 8-, 13- and 16-moment transport formulations of the polar wind, Ann. Geophys., 11, 443-469, 1993.

Blelly, P.-L., Lilensten, J., Robineau, A., Fontanari, J., and Alcaydé, D.: Calibration of a numerical ionospheric model with EISCAT observations, Ann. Geophys., 14, 1375-1390, 1996a,

SRef-ID: 1432-0576/ag/1996-14-1375.

Blelly, P.-L., Robineau, A., Lilensten, J., and Lummerzheim, D.: 8moment fluid models of the terrestrial high-latitude ionosphere between 100 and $3000 \mathrm{~km}$, Solar Terrestrial Energy Program (STEP) : Handbook of Ionospheric Models, ed. Schunk, R. W., 53-72, 1996b.

Carlson, H. C., Oksavik, K., Moen, J., van Eyken, A. P., and Guio, P.: ESR mapping of polar-cap patches in the dark cusp, Geophys. Res. Lett., 29-(10), 24(1-4) doi:10.1029/2001GL014 087, 2002.

Codrescu, M. V., Fuller-Rowell, T. J., and Foster, J. C.: On the importance of E-field variability for Joule heating in the highlatitude thermosphere, Geophys. Res. Lett., 22, 2393-2396, 1995.

Codrescu, M. V., Fuller-Rowell, T. J., and Kutiev, I. S.: Modeling the F layer during specific geomagnetic storms, J. Geophys. Res., 102, 14315-14330, 1997.

Crowley, G., Ridley, A. J., Deist, D., Wing, S., Knipp, D. J., Emery, B. A., Foster, J., Heelis, R., Hairston, M., and Reinisch, B. W.: Transformation of high-latitude ionospheric $\mathrm{F}$ region patches into blobs during the March 21, 1990, storm, J. Geophys. Res., 105, 5215-5230, 2000.

Culot, F., Lathuillère, C., Lilensten, J., and Witasse, O.: The OI $630 \mathrm{~nm}$ and $557.7 \mathrm{~nm}$ dayglow measured by WINDII and modeled by TRANSCAR, Ann. Geophys., 22, 1947-1960, 2004, SRef-ID: 1432-0576/ag/2004-22-1947.

David, M., Sojka, J. J., Schunk, R. W., and Heelis, R.: Relative solar and auroral contribution to the polar F region: Implications for National Space Weather Program, J. Geophys. Res., 107-(A10), SIA-15(1-8) doi:10.1029/2001JA009 167, 2002.

Diloy, P.-Y., Robineau, A., Lilensten, J., Blelly, P.-L., and Fontanari, J.: A numerical model of the ionosphere, including the Eregion above EISCAT, Ann. Geophys., 14, 191-200, 1996,

\section{SRef-ID: 1432-0576/ag/1996-14-191.}

Emery, B., Lathuillère, C., Richards, P. G., Roble, R. G., Buonsanto, M. J., Knipp, D. J., Wilkinson, P., Sipler, D. P., and Niciejewski, R.: Time dependent thermospheric neutral response to the 2-11 November 1993 storm period, J. Atmos. Terr. Phys., 61, 329-350, 1999.

Fedder, J. A., Slinker, S. P., and Lyon, J. G.: A comparison of global numerical simulation results to data for the 27-28 January 1992
Geospace Environnment Modellig challenge event, J. Geophys. Res., 13, 14 799-14 810, 1998.

Foster, J. C., Holt, J. M., Musgrove, R. G., and Evans, D. S.: Ionospheric convection associated with discrete levels of particle precipitation, Geophys. Res. Lett., 13, 656-659, 1986.

Fuller-Rowell, T. J. and Evans, D. S.: Height-integrated Pedersen and Hall conductivity patterns inferred from the TIROS-NOAA satellite data, J. Geophys. Res., 92, 7606-7618, 1987.

Fuller-Rowell, T. J., Codrescu, M. V., Risbeth, H., Moffett, R. J., and Quegan, S.: On the seasonal response of the thermosphere and ionosphere to geomagnetic storms, J. Geophys. Res., 101, 2343-2354, 1996.

Galand, M.: Introduction to special section: Proton precipitation into the atmosphere, J. Geophys. Res., 106, 1-6, 2001.

Galand, M., Lilensten, J., Kofman, W., and Sidje, R. B.: Proton transport model in the ionosphere 1. Multistream approach of the transport equations, J. Geophys. Res., 102, 22 261-22 272, 1997.

Hedin, A. E., Spencer, N. W., Biondi, M. A., Burnside, R. G., Hernandez, G., and Johnson, R. M.: Revised global model of thermosphere winds using satellite and ground-based observations, J. Geophys. Res., 96, 7657-7688, 1991.

Hedin, A. E., Buonsanto, M. J., Codrescu, M., Duboin, M.-L., Fesen, C. G., Hagan, M. E., Miller, K. L., and Sipler, D. P.: Solar activity variations in midlatitude thermospheric meridional winds, J. Geophys. Res., 99, 17 601-17 608, 1994.

Hubert, D.: Non-Maxwellian velocity distribution functions and incoherent scattering of radar waves in the auroral ionosphere, J. Atmos. Terr. Phys., 46, 601-611, 1984.

Kelly, J. and Wickwar, V. B.: Radar measurements of the highlatitude ion composition between 140 and $300 \mathrm{~km}$ altitude, J. Geophys. Res., 86, 7617-7626, 1981.

Lathuillère, C., Menvielle, M., Lilensten, J., Amari, T., and Radicella, S. M.: From the Suns atmosphere to the Earths atmosphere: an overview of scientific models available for space weather developments, Ann. Geophys., 20, 1081-1104, 2002,

SRef-ID: 1432-0576/ag/2002-20-1081.

Lathuillère, C.: Ion Composition Response to Auroral Energy Inputs in the Lower F Region, Ann. Geophys., 5, 449-454, 1987.

Lathuillère, C. and D. Hubert, D.: Ion composition and ion temperature anisotropy in periods of high electric fields from incoherent scatter observations, Ann. Geophys., 7, 285-296, 1989.

Lathuillère, C., Blelly, P. L., Lilensten, J., and Gaimard, P.: Storm effects on the ion composition, Adv. Space Res., 20(9), 1699 1708, 1997.

Leblanc, F., Hubert, D., and Blelly, P. L.: Comparison of the generalized and bi-Maxwellian multimoment multispecies approaches of the terrestrial polar wind, J. Geophys. Res., 105, 2551-2562, 2000.

Lilensten, J. and Blelly, P. L.: The TEC and $F_{2}$ parameters as tracers of the ionosphere and thermosphere, J. Atmos. Solar-Terr. Phys., 64, 775-793, doi:10.1016/S1364-6826(02)00 079-2, 2002.

Lilensten, J. and Galand, M.: Proton-electron precipitation effects on the electron production and density above EISCAT (Troms $\varnothing$ ) and ESR, Ann. Geophys., 16, 1299-1307, 1998,

SRef-ID: 1432-0576/ag/1998-16-1299.

Lilensten, J., Blelly, P. L., Kofman, W., and Alcaydé, D.: Auroral ionospheric conductivities: a comparison between experiment and modeling, and theoretical $\mathrm{F}_{10.7}$-dependent model for EISCAT and ESR, Ann. Geophys., 14, 1297-1304, 1996,

SRef-ID: 1432-0576/ag/1996-14-1297.

Lummerzheim, D. and Lilensten, J.: Electron transport and energy degradation in the ionosphere: Evaluation of the numerical solu- 
tion, comparison with laboratory experiments and auroral observations, Ann. Geophys., 12, 1039-1051, 1994,

\section{SRef-ID: 1432-0576/ag/1994-12-1039.}

Mantas, G. P.: Theory of photoelectron thermalization and transport in the ionosphere, Planet. Space Sci., 23, 337-354, 1975.

McEwen, D. J., Harris, D. P., MacDougall, J. W., and Grant, I. F.: Drifting F-Layer Patches over the Magnetic Pole, J. Geomag. Geoelec., 47, 527-537, 1995.

Millward, G. H., Moffett, R. J., Balmforth, H. F., and Rodger, A. S.: Modeling the ionospheric effects of ion and electron precipitation in the cusp, J. Geophys. Res., 104, 24 603-24 612, 1999.

Opal, C. B., Peterson, W. K., and Beaty, E. C.: Measurement of secondary electron spectra produced by electron impact ionization of a number os simple gases, J. of Chem. Physics, 55, 41004106, 1971.

Oznovich, I. and McEwen, D. J.: Auroral emissions at the North Magnetic Pole. A 17 February, 1993 Case study, J. Geomag. Geoelec., 46, 861-871, 1994.

Peymirat, C. and Fontaine, D.: Numerical simulation of magnetospheric convection including the effect of field-aligned currents and electron precipitation, J. Geophys. Res., 99, 11 155-11 176, 1994.

Pitout, F. and Blelly, P.: Electron density in the cusp ionosphere: increase or depletion ?, Geophys. Res. Lett., 30, SSC-2 (1-4) doi:10.1029/2003GL017 151, 2003.

Raeder, J., Berchem, J., and Ashour-Abdalla, M.: The Geospace Environnement Modelling Grand Challenge: Results from a Global Geospace Circulation Model, J. Geophys. Res., 103, 14 787-14 797, 1998.

Rich, F. J., Gussenhoven, M. S., and Greenspan, M. E.: Using simultaneous particle and field observations on a low altitude satellite to estimate Joule heat energy flow into the high-latitude ionosphere, Ann. Geophys., 5, 527-534, 1987.

Richmond, A. D.: Assimilative mapping of ionospheric electrodynamics, Adv. Space Res., 12, 59-68, 1992.

Richmond, A. D. and Kamide, Y.: Mapping electrodynamic features of the high-latitude ionosphere from localized observations: technique, J. Geophys. Res., 93, 5741-5759, 1988.

Robineau, A., Blelly, P.-L., and Fontanari, J.: Time-dependent models of the auroral ionosphere above EISCAT, J. Atmos. Terr. Phys., 58, 257-271, 1996.
Robinson, R. M., Vondrak, R. R., Miller, K., Dabbs, T., and Hardy, D.: On calculating ionospheric conductances from the flux and energy of precipitating electrons, J. Geophys. Res., 92, 25652569, 1987.

Roble, R. G.: On forecasting thermospheric and ionsopheric disturbances in space weather events, Geophysical Monograph 125, edited by Song, P., Singer, H. J., and Siscoe, G. L., 369-375, 2001.

Schunk, R. W.: Ionospheric climatology and weather disturbances: A tutorial in Space Weather, Geophysical Monograph 125, edited by Song, P., Singer, H. J., and Siscoe, G. L., 359-368, 2001.

Slinker, S. P., Fedder, J. A., Emery, B. A., Baker, K. B., Lummerzheim, D., Lyon, J. G., and Rich, F. J.: Comparison of global MHD simulations with AMIE simulations for the events of 19 20 May 1996, J. Geophys. Res., 104, 28 379-28 395, 1999.

St Maurice, J.-P. and Schunk, R.: Auroral ion velocity distributions for a polarization collision model, Planet. Space Sci., 25, 243 260, 1977.

Strickland, D. J., Book, D. L., Coffey, T. P., and Fedder, J. A.: Transport equation techniques for the deposition of auroral electrons, J. Geophys. Res., 81, 2755-2764, 1976.

Swartz, W. E. and Nisbet, J. S.: Revised calculations of the F region ambient electron heating by photoelectrons, J. Geophys. Res., 77, 6259-6261, 1972.

Valladares, C. E., Alcaydé, D., Rodriguez, J. V., Ruohoniemi, J. M., and van Eyken, A. P.: Observations of plasma density structures in association with the passage of traveling convection vortices and the occurrence of large plasma jets, Ann. Geophys., 17, 1020-1039, 1999,

SRef-ID: 1432-0576/ag/1999-17-1020.

Vontrat-Reberac, A., Fontaine, D., Blelly, P. L., and Galand, M.: Theoretical predictions of the effect of cusp and dayside precipitation on the polar ionosphere, J. Geophys. Res., 106, $28857-$ $28874,2001$.

Yoshida, N., Watanabe, S., Fukunishi, H., Sakanoi, T., Mukai, T., Hayakawa, H., Matsuoka, A., Kasahara, Y., Fujii, R., Nozawa, S., and Ogawa, Y.: Coordinated Akebono and EISCAT observations of suprathermal ion outflows in the nightside inverted-V region, J. Atmos. Solar-Terr. Phys., 62, 449-465, doi:10.1016/S1364-6826(00)00 012-2, 2000. 